This paper:

- Addresses the question of the environment, which is a major concern for the general population.

- Points out the efficiency of mercury traps and the ethics of using them.

- Puts into perspective the limited impact that dental mercury has on the environment.

- Distinguishes between inorganic and organic forms of mercury and the impact that these different chemical forms of mercury can have on health.

- Dispels the myth that mercury from dental amalgam presents a health hazard to the dentist and the patient.

- Points out that the controversy surrounding the use of dental amalgam has been as much a political issue as a scientific one.

\title{
Putting dental mercury pollution into perspective
}

\author{
D. W. Jones ${ }^{1}$
}

This paper deals with the issue of amalgam waste from dental offices. The aim is to put into perspective the very small contribution of dental mercury to the overall volume of mercury discharged into the environment each year. While the amount discharged from dental offices is very small compared to other sources, the amount discharged into the environment from amalgam fillings in people's mouths is estimated as less than $2 \%$ of the amount from dental offices. At least 50\% of mercury in the environment comes from natural sources. The major source of man-made mercury pollution is the industrial burning of fossil fuels. It is important to distinguish between inorganic mercury and organic mercury in terms of the impact on the health of the population.

\section{A POLITICAL ISSUE}

The discharge of mercury/amalgam-contaminated wastes has been regulated in a number of countries as part of a point source reduction strategy, even though it has been documented that by adopting appropriate mercury hygiene measures, including installation of amalgam-separating devices, the environmental impact of amalgam use in dentistry is minimal. The issue of disposal of dental amalgam waste has been in the news from time to time during the past few years with the dental profession making the headlines in the media.

A pilot project to study the effectiveness of amalgam separators compliant with the international standard ISO-11143 on Prince Edward Island in Canada would be expected to be seen by the public as a positive and responsible approach by the dental profession. However, a major question raised by the media was, why if amalgam is safe in my mouth is it a problem if it enters the sewage system? It is also clear that within the dental profession the policy of adopting the use of amalgam separators is not universally agreed. The decision by the cities

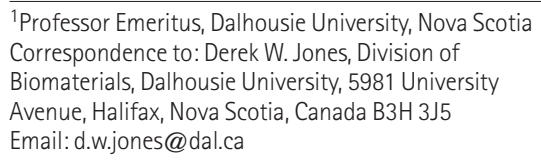

\section{Refereed Paper}

Received 31.03.03; Accepted 30.10.03

doi:10.1038/sj.bdj.4811564

๑ British Dental Journal 2004; 197: 175-177 of Toronto and Montreal to introduce city bylaws dealing with release of mercury from dental offices has created concern in the minds of some members of the profession and confusion with the public. In fairness this concern by some members of the profession relates to the difficulty of compliance with the enforcement of sewer bylaws relating to mercury pollution.

Over the past several years the controversy surrounding the use of dental amalgam has been as much a political issue as a scientific one. The question of environmental pollution by dental waste is clearly a political issue. In 1997 I attended a symposium in Toronto ${ }^{1}$ that made a very worthy and sincere attempt to come up with answers to the elimination (or more realistically reduction) of 'Anthropogenic' (man made) mercury in the environment by means of a North American partnership. Both Canadian and U.S. government agencies agree that the reduction of mercury pollution on only one side of the Great Lakes is not a sensible approach. At the time I stated that the mercury issue was as much a question of politics and commercial compromise as it is of science and technology. I also pointed out at the time that the amalgam issue in dentistry would inevitably be made use of in the environmental power-game to be played out over the next several years. Dentistry is indeed a pawn in the chess game of industrial pollution politics being undertaken by Canadian and U.S. government agencies. Canada has a total of 14 federal and provincial ministers monitoring the chessboard.

\section{MERCURY IN THE ENVIRONMENT}

It is generally accepted that about 50\% of mercury found in the environment are derived from natural sources, such as ocean evaporation and rock erosion. Even trees can extract mercury along with the nutrients they need from the soil and then transport it into the atmosphere. The quantity of mercury released from trees has been found to significantly increase during daylight hours, however, this is not an argument to cut down the Brazilian rain forests in order to limit mercury pollution. While the anthropogenic mercury can be calculated from emissions from industrial and other sites, the level of natural mercury is based on the difference calculated from the total, and may be considerably higher than the 50\% estimated. According to experts, the geothermal contribution is very difficult to determine and may be significantly underestimated. Incredibly, about $42 \%$ of environmental pollution by mercury is due to the combustion of solid fuels. Without question, the burning of fossil fuels is the major area in which it is possible to make a significant impact on the reduction of mercury pollution. The U.S. EPA estimates that solid-waste incinerators and coal-fired power plants are responsible for more than $80 \%$ of the man-made mercury emissions in the United States.

In the past 20 years or so the amount of mercury entering the environment has 
increased by a factor of three in both fresh water and oceans. Acid rain, another product from industrial pollution can also increase the mercury eroded from rocks.

Recognition of the problem of mercury pollution of the environment has resulted in significant curtailment of the use of mercury by some segments of industry during the past 35 years.

The tragic Minemata disaster that came to light in 1956 was a result of the discharging of industrial waste inorganic mercury into the Minemata bay which is $900 \mathrm{~km}$ southwest of Tokyo. The Chisso Corporation dumped mercury compounds into the bay over a period of several years. The mercury collected in the sludge at the bottom of the bay and in the absence of oxygen was converted into organic mercury compounds such as methyl and ethyl mercury. The organic mercury was taken up by the plankton, eaten by the small fish that were eaten by the medium sized fish that were eaten by the big fish that eventually were eaten by humans. The result was a mass poisoning of the population in the vicinity of Minamata. The fish in Minamata bay were found to have mercury levels as high as 24 parts per million. That is $24 \mathrm{\mu g} \mathrm{g}^{-1}$ of fish. Eating 40 grams of fish with $24 \mathrm{ppm}$ of mercury would mean exposure to $960 \mu \mathrm{g}$ of organic mercury with an absorption in the GI tract of 90\%. It is possible to calculate how many amalgam surfaces would be equivalent to eating 40 gram of fish containing 24 ppm of mercury. The answer is you would need to have a staggering 10,800 amalgam surfaces in your mouth in order to absorb the equivalent amount of mercury. The level of $24 \mathrm{ppm}$ of mercury in the Japanese tragedy represented a major health hazard; in fact the limit now placed on mercury in fish in North America is $1 \mathrm{ppm}$. The level at which the most sensitive individual would experience sub clinical symptoms of mercury poisoning is $300 \mu \mathrm{g}$ day $^{-1}$. $^{2}$ This value of $300 \mu$ day $^{-1}$ (or $4.3 \mu \mathrm{g}$ $\mathrm{Hg}$ day $^{-1} \mathrm{~kg}$ body weight ${ }^{-1}$ ) was assigned as the lowest observable adverse effect level for mercury ingested from fish. This level was used by WHO to calculate using uncertainty factors the ADI (acceptable daily intake) of $40 \mathrm{ug}$ day $^{-1}$. In order to reach a level of 300 $\mu \mathrm{g}$ day $^{-1}$ from dental amalgam alone you would need to have a total of 3,750 amalgam surfaces in your mouth. Since normal individuals have a maximum of 32 teeth this is clearly impossible.

Triggered by the industrial mercury pollution problem in Minamata bay in Japan, Swedish scientists in the 1950s and 60s began to investigate industrial pollution due to mercury. In 1960 the Swedish pulp and paper industry was using $24,000 \mathrm{~kg}$ of mercury a year. Fish in the Swedish lakes were contaminated by mercury. Studies of the Swedish bird population demonstrated significant mercury levels. Seed eating birds were examined, since methyl mercury was at the time being used as an anti-fungal seed dressing. The seed was eaten by birds and small rodents and accumulated in their tissues. Mercury deposited in bird's feathers taken from museum specimens of seed-eating birds from the year 1820 to the 1950s correlated with the use of the seed dressing. Analysis of mercury in the feathers of birds of prey, especially fish eating birds began to increase from about 1890 onwards and correlated with the rise of the industrial revolution. Sweden to its credit banned the use of mercury in the pulp and paper industry and the use of methyl mercury coated seed 36 years ago in $1966 .^{3}$

Recent research in Canada has also studied birds as a means of indicating mercury pollution. ${ }^{4}$ According to Neil Burges of Environment Canada Wildlife Service, the impact of mercury pollution in Nova Scotia and New Brunswick has resulted in high levels of mercury in the loon population. Data indicates a trend of increasing levels of mercury in the loon population from the west to the east coast. The levels are double in the lakes in Kejimkujik National Park in Nova Scotia compared to eastern Canada. The assumption is that it is the prevailing weather patterns that bring the industrial mercury pollution from south of the border. Studies indicate that at levels above $0.36 \mathrm{ppm}$ in fish, the loons fail to produce eggs that hatch. Apparently loons are an ideal bird to study since they lay eggs long after locating on the lake and eating the fish.

A four foot fluorescent lamp tube contains some 15 to $20 \mathrm{mg}$ of mercury (a milligram is one thousandth of a gram). In 199615 tons of Hg was contained in fluorescent lamps in North America. ${ }^{5}$ Improved manufacturing techniques have reduced this from 27 tons in 1990. In 1997 it was stated that close to 8 tons of mercury from fluorescent lamps end up in landfill and incinerator plants and is thus discharged (unlike dental mercury waste) in the form of vapour into the environment each year in North America. This source of mercury is nine times greater than the estimate of 781 $\mathrm{kg}$ from Canadian dental offices. ${ }^{6}$ Given the level of pollution from the above industrial sources, the problem of mercury from dental offices is put into perspective. Estimates of mercury put into the sewer system by Canadian dentistry is incredibly small in comparison to the worldwide release of mercury that has been estimated as 7,000 tons or 6.3 million $\mathrm{kg} .{ }^{5}$ A further estimate that is incredibly three to four times higher puts the global figure between 20,00030,000 tons of mercury discharged into the environment each year as a result of human activities. ${ }^{7}$ Whatever the real number is for total mercury released into the environment on a global scale, the amount released from dental procedures and dental amalgam is not a significant contributor to the problem.

\section{POLLUTION FROM DENTAL OFFICES}

An estimate of $781 \mathrm{~kg}$ of mercury put into the sewer system by Canadian dentists in 1995 has been made. However, it is important to note that the material discharged into sewage would be predominantly in the form of an amalgam alloy. The simple fact is that any mercury which is combined into an amalgam with silver copper and zinc will not be readily available as a free contaminant in the sewer system, but may only release a small proportion of mercury into the sewer over time as corrosion takes place. It is clear that calculations using a value such as $781 \mathrm{~kg}$ a year can significantly overestimate the volume of free mercury that is released into the sewer system from dental offices. Data dealing with mercury derived from dental amalgam waste may well relate to deposits into the sewage sludge that has occurred at a much earlier time than the time of monitoring. The origin of pollution may belong to an era when amalgam usage was much higher and was used in the non-capsulated form. Even if mercury from Canadian dental offices was as high as 2 metric tons a year it would represent only a very small proportion of terrestrial mercury pollution. One estimate is that worldwide dental mercury pollution is of the order of 3-4\%; furthermore this amount is declining each year. ${ }^{7}$ Thus the dental contribution is quite insignificant compared with industrial pollution and combustion of fossil fuels.

\section{ORGANIC AND INORGANIC MERCURY}

It is important to recognize that mercury exists in both the inorganic and organic form. The inorganic form is the silver liquid metal that is mixed with silver and copper alloy in order to form dental amalgam. The organic form occurs when mercury combines with carbon and hydrogen to form compounds such as methyl mercury. The organic mercury compounds can be formed in the absence of oxygen in the presence of bacteria and are much more insidious since they can traverse lipid membranes, (Lipids are organic fatty substances insoluble in water). Organic mercury can readily enter the central nervous system and the brain. The oily tissues of fish also readily accumulate and retain organic mercury. Thus, although mercury used in the dental office is only in the inorganic form, release into the environment will allow it to be available for conversion into the more dangerous organic form. Inorganic mercury discharged into the environment, under certain conditions in the absence of oxygen in the sludge at the bottom of a lake or the 
ocean (or in the sewage system) and in the presence of bacteria can be converted to the more dangerous organic form. In the aqueous environment the organic mercury can be taken up in plankton, which is eaten by small fish, the small fish are in turn eaten by medium sized fish that end up being eaten by large fish. The U.S. FDA have issued an advisory in 2001 that pregnant women and women considering pregnancy should not eat shark, swordfish, king mackerel or tilefish because they could contain enough mercury to harm an unborn infant's nervous system. The advisory says that young children and nursing women also should avoid those species of fish, which tend to live longer and have higher mercury concentrations in their tissues.

The level at which sub-clinical symptoms may occur due to mercury has been set at $300 \mu$ day $^{-1}$ by WHO. Health Canada in 1998 set a new guideline for young children and women of childbearing age with a conservative level of exposure to mercury at 95\% below the above level at which health effects have been demonstrated.

\section{TOLERANCE TO MERCURY}

The question that needs to be addressed is: are regulatory agencies overreacting to the presence of mercury in food and mercury released from dental procedures? The prevalence of mercury from natural sources in the earth's crust coupled with the relative ease with which it is chemically modified and mobilised for exchange between land, air and aquatic environments, imply that living systems have been in contact with mercury throughout biological evolution. Thus, as Dr. Thomas Clarkson $^{8}$ has speculated it is reasonable to assume that there may well be a level of tolerance to mercury by living organisms.

\section{MORAL AND ETHICAL STANCE}

The dental profession worldwide has been extremely moral and ethical in dealing with the perceived problem of mercury from dental amalgam fillings. The use of alternative materials to amalgam represents a considerable economic advantage to dentistry. The same can be said about the dental profession undertaking a study of curtailment of pollution from the dental office, in that they are prepared to evaluate it even though the dental office contribution is only a very small part of a major environmental pollution problem. It is true to say that if the mercury pollution from dentistry was reduced to zero tomorrow it would not have an impact on the mercury problem worldwide. Indeed even if it was possible to reduce the industrial emissions to zero tomorrow, the global impact would only be very minor due to the re-emission and cycling of mercury that is currently available within the natural system. Even though dentistry is a pawn in the chess game of industrial pollution politics, perhaps it is appropriate that the profession stands tall and demonstrate that they have a high ethical code; and are prepared to take a responsible approach to making even a minor contribution to reducing mercury pollution. Undoubtedly the dental profession can lead the way by adopting a positive approach to the environmental issue, however, the limited impact that they can make is more of a political statement or gesture, rather than solving the mercury pollution issue. The majority of the dental profession has always shown a very ethical and responsible attitude to the often perceived problem with dental amalgam. If all Canadian dental offices had ISO 1143:1999 compliant amalgam separators in theory it would be possible to reduce the 781 $\mathrm{kg}$ down to $7.81 \mathrm{~kg}$.

\section{MERCURY IN THE MOUTH}

The general public who hear and read that mercury from a dental office must not go into the sewage system are naturally concerned about the mercury released from their amalgam restorations. The media has often posed the question, why is mercury OK in your mouth but not in the environment? In the first case it should be realized that 'inorganic mercury vapour' is only released very slowly from dental amalgam fillings. A typical amalgam restoration of $0.65 \mathrm{~g}$ would take 1,680 years to lose all of the combined mercury at the very slow rate that mercury vapour is released.

It has been estimated that $0.534 \mu \mathrm{g}$ of mercury vapour is released in 24 hours from each amalgam surface. ${ }^{9}$ A microgram $(\mu \mathrm{g})$ is one millionth of a gram (and an ounce is equal to 25 grams), thus $0.534 \mu \mathrm{g}$ is a very small amount. An individual would have to have 490 amalgam surfaces for there to be enough mercury vapour and ionic mercury given off to reach the maximum exposure limit set by the World Health Organization. Only some $15.25 \%$ of the very small amount of inorganic mercury released from amalgam fillings (15.25\% of 0.534 day $^{-1}$ per surface $=0.08 \mu \mathrm{g}$ day $^{-1}$ ) is absorbed into the blood stream from the lungs and GI tract. In contrast some 90\% of the organic mercury contained in food predominantly fish is absorbed into the body. Six times as much organic mercury is absorbed compared to the inorganic form. Thus the general public should not be concerned about very small amount of mercury released from their amalgam restorations.

Another point that has been made is that the pollution from dental offices represents one problem but what about the pollution into the environment from the mouths of people containing amalgam restorations? It is clear that some inorganic mercury released from dental restorations of Canadians is exhaled and a further amount passes through their system and is discharged into the sewer waste. We have no accurate figures on the number of amalgam fillings in the Canadian population, however, if we assume that 30 million Canadians have 3 amalgam surfaces each giving a total of 90 million amalgam surfaces, these fillings would release $47.7 \mathrm{~g}$ day $^{-1}$ or $17.41 \mathrm{~kg}$ year ${ }^{-1}$. The total mercury excreted into the sewer would be $12.15 \mathrm{~kg}$. The total released into atmosphere (by exhaling vapour) would be $2.18 \mathrm{~kg}$. The combined total of mercury released into environment by these 30 million people would be $14.33 \mathrm{~kg}$. The total body burden of the 30 million Canadians would be $2.66 \mathrm{~kg}$ or about $100 \mu \mathrm{g}$ per person. This $14.33 \mathrm{~kg}$ total is only $1.83 \%$ of the $781 \mathrm{~kg}$ estimated to have been released by Canadian dentists in 1995.

However, we must also remember that the discharge of mercury directly in the sewer system provides the ideal opportunity for the formation of the more bio-available organic mercury compounds. This discharge of dental mercury into the environment represents a very minor contribution compared with industrial pollution and combustion of fossil fuels. The public should be concerned about the massive industrial pollution and discharge of mercury into the environment that is likely to significantly increase with the environmental policies being adopted by the US administration. The US requirement for increased electrical power generation and the rejection of the Kyoto agreement are major factors that will effect mercury pollution.

Clearly the dental contribution to environmental pollution is very, very small and getting smaller. However, if we can prevent even a small amount of inorganic mercury entering the environment where it can combine to form organic mercury and end up in your next can of a fish, we should certainly try to do it.

1. Mercury Elimination and Reduction Symposium, Pollution Probe. Toronto May 5-6th 1997.

2. Amdur M O, Doull J, Klassen C D. Cassarett and Doull's Toxicology: The basic science of poisons. New York: Pergamon Press, 1991).

3. Jones D W. The enigma of amalgam in dentistry. J Can Dent Assoc. 1993; 59: 155-166.

4. Burges N. Paper given at Mercury Elimination and Reduction Symposium Pollution Probe, Toronto May 5-6th 1997.

5. Chong R. Mercury reduction and product stewardship. Paper presented at Mercury Elimination and Reduction Symposium Pollution Probe, Toronto May 5-6th 1997.

6. Environment Canada ARET Secretartiat. Final report: Inventory of users and release of mercuryduring product life cycle. Ottawa: November 1999.

7. Chin $\mathrm{G}$, et al. The environmental effects of dental amalgam. Aust Dent J 2000 45: 246-249.

8. Clarkson T. Mercury. In: Nriagu J O. Ed. Changing Metal Cycles and Human Health. Berlin: SpringerVerlag, 1984, p. 285-309.

9. Jones D W. Exposure and Absorption and the Crucial Question of Limits for Mercury. J Can Dent Assoc. 1999; 65: 788-792. 